\title{
ASPECTOS ECONÔMICOS DA CADEIA PRODUTIVA DOS ÓLEOS DE ANDIROBA (Carapa guianensis Aubl.) E COPAÍBA (Copaifera multijuga Hayne) NA FLORESTA NACIONAL DO TAPAJÓS - PARÁ
}

\author{
Anadalvo Juazeiro dos Santos ${ }^{1}$, Fabíola Gisela Pinto de Queiroz Guerra ${ }^{2}$ \\ ${ }^{1}$ Eng. Florestal, Dr., Depto. Economia Rural e Extensão, UFPR, Curitiba, PR, Brasil - ajsantos@ufpr.br \\ ${ }^{2}$ Enga. Florestal, M.Sc., Curitiba, PR, Brasil-fgpqueiroz@ig.com.br \\ Recebido para publicação: 17/11/2008 - Aceito para publicação: 26/05/2009
}

\begin{abstract}
Resumo
Os produtos florestais não-madeireiros constituem importante fonte de renda para a população amazônica, como é o caso dos óleos vegetais de andiroba e copaíba para as comunidades da Floresta Nacional do Tapajós. Este artigo tem por objetivo descrever a cadeia produtiva e analisar, do ponto de vista econômico, a comercialização desses óleos na Flona. A metodologia utilizada constituiu-se em uma pesquisa de campo, na qual foram aplicados questionários junto a extrativistas, associação e comerciantes dos óleos, a fim de se coletarem dados econômicos. A partir desses dados, foram calculados margem bruta e markup de comercialização. Também foi construído o fluxograma que apresenta os diversos atores que compõem a cadeia produtiva desses produtos. A pesquisa demonstrou a existência de 24 famílias extrativistas, organizadas em uma associação intercomunitária, que é responsável pela comercialização dos óleos. Os resultados indicaram que, na comercialização dos produtos, os intermediários (atacado e varejo) se apropriam da maior parte dos ganhos em relação ao preço pago pelo consumidor. Observou-se que a carência de informações que os extrativistas têm a respeito do mercado desses produtos é um fator limitante para uma maior geração de renda, além da falta de conhecimento de técnicas de agregação de qualidade e valor aos produtos.

Palavras-chave: Óleos vegetais; Floresta Nacional do Tapajós; produto florestal não-madeireiro.
\end{abstract}

\begin{abstract}
Economical aspects of the productive chain of oils of andiroba and copaiba in the National Forest of the Tapajos - Para. The No Timber Forest Products constitute important source of income for the amazonian population, as it is the case of vegetal oils of andiroba and copaiba for the communities of the National Forest of the Tapajos. This article has for objective to describe the productive chain and to analyze the commercialization, of the economic point of view, of these oils in the Forest. The used methodology consisted in a field research, through applied questionnaires to extractors, association and traders of oils, with the objective of obtaining economical data. From these data the index of gross commercialization margins and markup of commercialization were calculated. We also built a flow concerning all the actors that compose the marketing chain. The research demonstrated the existence of 24 extractors families, organized in association, that it is responsible for the commercialization of oils. The results had indicated that, in the commercialization of the products, the intermediate (attacked and retail) if appropriate of most of the profits in relation to the paid price for the consumer. It was observed that the lack of information that the extractors have regarding the market of these products is a limit factor for a bigger generation of income, beyond the lack of knowledge of techniques of aggregation of quality and value to the products.
\end{abstract}

Keywords: Vegetal oils; Tapajos National Forest; no timber forest products.

\section{INTRODUÇÃO}

A análise econômica das florestas tropicais tem tradicionalmente evidenciado a colheita de madeira ou a conversão da terra para agricultura ou produção pecuária (CASTELLANI, 2006). Entretanto, percebe-se que essa valorização apenas da madeira vem sendo gradualmente modificada, em 
virtude da gama enorme de outros produtos e benefícios que a floresta propicia aos habitantes locais (SANTOS, 2003).

Nesse cenário, surge o reconhecimento do valor dos produtos florestais não-madeireiros (PFNMs) das florestas tropicais (DE BEER; MCDERMOTT, 1989; PETERS et al., 1989) como uma opção para se explorar a riqueza biológica de florestas tropicais sem prejudicá-las e, ao mesmo tempo, estimular o desenvolvimento rural (FAO, 1995). Se manejados corretamente, a estrutura e a função da floresta não são alteradas, e sua extração não envolve a destruição dos recursos naturais. Assim, o uso desses produtos aparece como uma estratégia de conservação da floresta e manutenção de sua biodiversidade (NEPSTAD; SCHWARTZMAN, 1992).

Segundo Castellani (2006), a forma mais comum de aproveitamento dos PFNMs é o extrativismo, entendido aqui como uma colheita arbitrária do material de acesso mais disponível na floresta, sem nenhuma previsão técnica ecológica de seu efeito sobre as populações e sem uma estimação de sua capacidade produtiva sustentável. A exploração das florestas centrada na produção de PFNMs pode ser ecológica e economicamente sustentável sempre que as taxas de extração não excedam o rendimento máximo sustentável.

Os PFNMs fazem parte de grandes mercados regionais e internacionais, e, durante séculos, produtos como especiarias, plantas medicinais, fragrâncias e resinas estimularam viagens de exploração e sustentaram rotas comerciais em todo o mundo (SHANLEY et al., 2005a). Constituem também matériaprima para várias indústrias que processam e produzem óleos essenciais, inseticidas, medicamentos, alimentos e corantes, entre outros. Além disso, a prática tem mostrado que o extrativismo de PFNMs vem, há décadas, junto com a agricultura de subsistência e a pesca, sendo um dos meios de sustentação das populações do Norte do Brasil, além de fazer parte da cultura desses povos (RUEDA, 2006).

Estima-se que os PFNMs respondem por até $25 \%$ da renda de cerca de um bilhão de pessoas no mundo (MOLNAR et al. 2004). Mesmo em países pós-industrializados, como os EUA, esses produtos oferecem uma rede de segurança que possibilita a sobrevivência de muitas pessoas em regiões insuficientemente servidas pela economia de mercado (EMERY, 2005).

Mas apenas nos últimos anos vem se dando um interesse crescente por parte das comunidades, indústrias e governo na promoção de sistemas florestais de gestão diversificada que incluam, além da madeira, outros produtos e benefícios derivados das florestas, como ferramenta para conservar os ecossistemas florestais (SHANLEY, 2005b).

No caso específico da Floresta Nacional do Tapajós (Flona Tapajós), consta nas diretrizes do seu plano de gestão a promoção do desenvolvimento em bases sustentáveis, por meio da geração de emprego e renda, promoção e estímulo das parcerias entre comunitários, instituições de pesquisa e empresas e a promoção da utilização e do uso comunitário dos recursos florestais madeireiros e não-madeireiros.

Na região amazônica, a utilização dos óleos da Carapa guianensis Aubl. (Meliaceae) e da Copaifera multijuga Hayne (Fabaceae), conhecidos por andiroba e copaíba, respectivamente, é uma prática tradicional das comunidades da região, além de uma importante fonte de renda. Esses óleos são muito utilizados na medicina natural, pois possuem propriedades cicatrizantes, anti-inflamatórias, antissépticas e antipiréticas.

O presente trabalho objetiva caracterizar a cadeia produtiva dos óleos vegetais de andiroba e copaíba e analisar alguns aspectos econômicos desses PFNMs, que constituem um dos meios de sustentação das comunidades tradicionais localizadas na Flona Tapajós/PA.

\section{MATERIAL E MÉTODOS}

A pesquisa foi realizada nos meses de julho de 2006 a junho de 2007, com 24 famílias extrativistas residentes nas comunidades Nazaré, Pedreira e São Domingos, localizadas na Flona Tapajós, que possui uma área de 544.927 hectares. A agricultura em regime de exploração familiar é a principal atividade dos moradores da Flona e visa o sustento da família e a venda de excedentes. Os dados foram obtidos em pesquisa de campo, através da aplicação de questionários aos extrativistas e à Associação Intercomunitária de Mini e Pequenos Produtores Rurais da Margem Direita do Tapajós de Piquiatuba a Revolta (ASMIPRUT), responsável pela elaboração do projeto de melhoria dos processos de produção e comercialização dos óleos no município de Santarém. 
Entre os itens abordados no questionário, estão custos de produção, preços praticados no mercado, quantidades extraídas e comercializadas, bem como os canais de comercialização.

Em seguida, foram identificados os principais componentes da cadeia produtiva, e elaborado seu fluxograma. Para analisar os ganhos nos diferentes elos da cadeia de comercialização, foram usados os conceitos de margem e markup de comercialização.

\section{RESULTADOS E DISCUSSÃO}

\section{Descrição dos atores que compõem a cadeia produtiva dos óleos vegetais de andiroba e copaíba}

O processo de produção do óleo de andiroba inicia-se com a coleta das sementes de andiroba na floresta. Já a extração do óleo de copaíba é realizada diretamente das árvores, através da perfuração do caule. Após a colheita, os produtos (sementes e óleo) são transportados nos ombros dos extrativistas, até os galpões das comunidades, onde ocorre a primeira etapa de beneficiamento. No caso da andiroba, o óleo é extraído das castanhas das sementes, através de um processo tradicional de cozimento e fermentação, que leva cerca de 15 dias. A segunda etapa é para a retirada de impurezas dos óleos, através do processo de peneiramento e filtragem. Em seguida, os óleos são embalados em galões (5 litros) e frascos plásticos (30 ml, $100 \mathrm{ml} \mathrm{e} 1$ litro). A partir daí, o fluxo pode ter dois destinos: associação ou consumidor final. A associação rotula as embalagens e comercializa para a rede atacadista. Os atacadistas, indústrias farmacêuticas e laboratórios nacionais e internacionais, beneficiam os óleos fabricando velas, sabonetes, cosméticos, remédios homeopáticos e até mesmo o óleo in natura diluído, e vendem para a rede varejista. Os varejistas, por sua vez, revendem os produtos para o consumidor final. A rede varejista é formada por estabelecimentos de diversos portes (lojas de produtos naturais, farmácias de manipulação e homeopáticas, mercados e feiras populares), localizados em diversas capitais do país, principalmente na região amazônica, e em alguns países da Europa (Figura 1). Todavia, pequena quantidade de óleo é comercializada diretamente pelas comunidades aos consumidores finais, geralmente turistas que estão visitando a Flona.

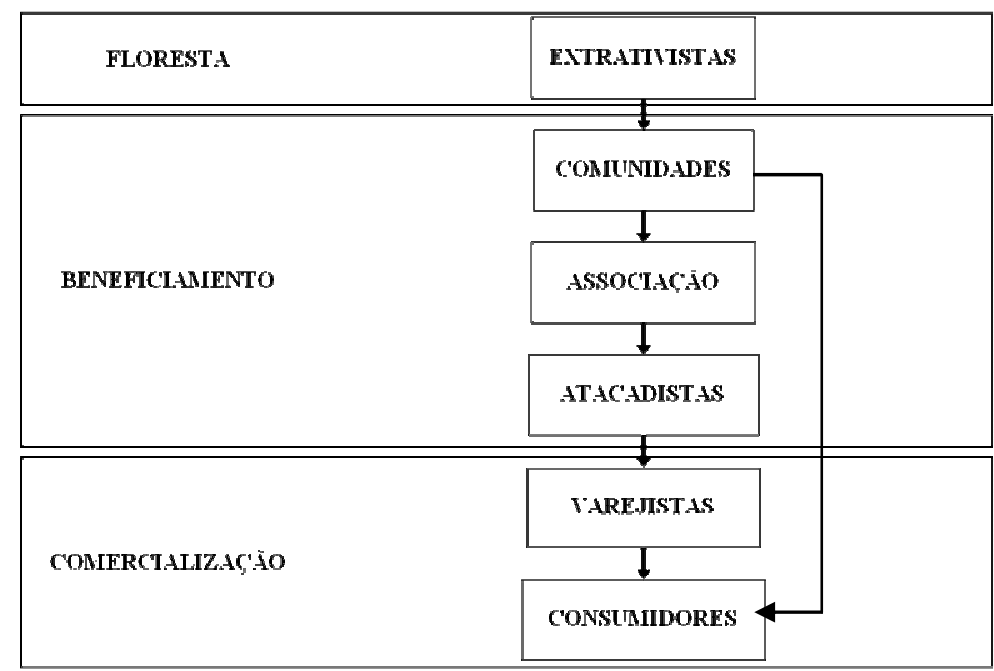

Fonte: Pesquisa realizada pelos autores.

Figura 1. Fluxograma da cadeia produtiva dos óleos vegetais de andiroba e copaíba na Flona Tapajós.

Figure 1. Flowchart of the productive chain of vegetal oils of andiroba e copaiba in the Forest Tapajos.

Observa-se que a cadeia produtiva dos óleos vegetais é bastante simplificada, operando com poucos agentes em todos os níveis, entretanto a falta de conhecimento do mercado para esses produtos apresenta-se como um fator limitante para seu desenvolvimento, assim como para uma maior geração de renda para as comunidades, uma vez que a maior parte da produção é comercializada por empresas privadas e não pela associação comunitária. Além disso, a falta de controle de qualidade dos óleos tem sido uma barreira de aceitação de alguns fornecedores dos óleos no mercado nacional e no exterior. 
Outros problemas identificados na cadeia foram a produção sazonal, que dificulta a oferta regular dos óleos e enfraquece o mercado, e o baixo grau de beneficiamento realizado pelas comunidades. Vale ressaltar que, quando os óleos são comercializados diretamente com os extrativistas, o preço do litro é de $\mathrm{R} \$ 15,00$, e quando comercializados através da associação para os atacadistas, o preço chega a $\mathrm{R} \$$ 60,00 para o óleo de andiroba e R \$30,00 para o de copaíba.

\section{Aspectos econômicos da comercialização dos óleos vegetais na Floresta Nacional do Tapajós}

Na produção dos óleos, contabilizam-se como custos principais para os extrativistas a mão de obra, paga em forma de diárias, os recipientes para armazenamento dos óleos, o frete para transportar a produção até a associação com sede em Santarém e os impostos, entre eles o Imposto sobre a Circulação de Mercadoria e Serviço (ICMS). É importante ressaltar que não são computados os custos com a terra, de onde são extraídas as sementes, já que a Flona trata-se de uma unidade de conservação.

Óleo vegetal de andiroba

No ano de 2006, as 24 famílias estudadas produziram 640 litros, venderam ao preço médio de R\$ $55,00 /$ litro (o preço de venda do óleo varia entre $\mathrm{R} \$ 45,00$ e $\mathrm{R} \$ 60,00$ ) e geraram uma receita bruta de $\mathrm{R} \$$ $35.200,00$. Os custos de produção somaram $R \$ 9.920,00$, representando um custo de $R \$ 15,50 /$ litro. O maior custo foi representado pelos impostos, $60 \%$, seguido dos utensílios utilizados para a extração do óleo, com aproximadamente $20 \%$. A mão de obra utilizada na coleta representou $15 \%$ dos custos. O menor custo foi representado pelo frete (4,5\% dos custos). A receita líquida média mensal gerada pala comercialização do óleo de andiroba para cada família foi de $\mathrm{R} \$ 95,16$, representando cerca de $27 \%$ do salário mínimo vigente na época (2006: $\mathrm{R} \$ 350,00)$.

No que se refere à margem de comercialização, evidenciou-se grande variação entre os diferentes atores que compõem a cadeia produtiva (Tabela 1).

Tabela 1. Preços e percentuais da margem de comercialização de produtos elaborados com óleo de andiroba.

Table 1. Prices and percentages of edge of commercialization of products elaborated with oil of andiroba.

\begin{tabular}{lccccc}
\hline Tipo & Variáveis & Produtor & Atacado & Varejo & Margem total \% \\
\hline Óleo in natura & Preço $(\mathrm{R} \$)$ & 55,00 & $250,00^{1}$ & $566,00^{2}$ & 90,3 \\
& Margem (\%) & 7 & 34,45 & 55,8 & \\
Vela & Preço (R\$) & 55,00 & $250,00^{3}$ & $333,00^{4}$ & 83,5 \\
& Margem (\%) & 11,9 & 58,6 & 24,9 & \\
\hline
\end{tabular}

${ }^{1}$ Os atacadistas beneficiam e vendem o óleo de andiroba in natura em frascos de $30 \mathrm{ml} .{ }^{2}$ Os varejistas vendem os frascos de $30 \mathrm{ml}$ por $\mathrm{R} \$ 17,00$, equivalendo a $\mathrm{R} \$ 566,00$ o litro. ${ }^{3} \mathrm{Os}$ atacadistas fabricam e vendem velas, que contêm $15 \mathrm{ml}$ do óleo de andiroba. ${ }^{4} \mathrm{Os}$ varejistas vendem as velas a $\mathrm{R} \$ 5,00$ a unidade, o que equivale a $\mathrm{R} \$ 333,00$ o litro de óleo de andiroba.

Observou-se que, para a comercialização do óleo in natura, $55,8 \%$ da margem de comercialização foram apropriados pelo varejista, enquanto o atacadista apropriou-se de $34,45 \%$, restando $7 \%$ para o produtor. A margem total de comercialização foi de $90,3 \%$, referindo-se à diferença entre o preço pago pelo consumidor e o preço pago ao produtor.

Na comercialização das velas, a margem total de comercialização foi de 83,5\%, e o atacadista se apropriou da maior parte dos ganhos em relação ao preço pago pelo consumidor $(58,6 \%)$. O varejista se apropriou de $24,9 \%$ e o produtor de $11,9 \%$.

A tabela 2 apresenta os preços e os markups de comercialização de produtos elaborados com óleo de andiroba.

Tabela 2. Preços e markup de comercialização de produtos elaborados com óleo de andiroba.

Table 2. Prices and commercialization markup of products elaborated with oil of andiroba.

\begin{tabular}{lccccc}
\hline Tipo & Variáveis & Produtor & Atacado & Varejo & Markup total \% \\
\hline Óleo in natura & Preço (R\$) & 55,00 & 250,00 & 566,00 & 929,1 \\
& Margem (\%) & 254,9 & 354,55 & 126,4 & \\
Vela & Preço (R\$) & 55,00 & 250,00 & 333,00 & 505,5 \\
& Margem (\%) & 254,9 & 354,55 & 33,2 & \\
\hline
\end{tabular}


Observou-se que o atacadista foi o principal responsável pela alteração do preço, aumentando em $354,55 \%$ o preço pago ao produtor, tanto para a comercialização do óleo in natura quanto das velas, enquanto o varejista acrescentou um markup de $126,40 \%$ na comercialização do óleo e de $33,20 \%$ na da vela para o consumidor. Este paga $929,10 \%$ a mais sobre o preço pago ao produtor na compra do óleo in natura, e 505,50\% na compra das velas. É importante ressaltar que os agentes atacadistas e varejistas possuem determinados custos de produção para o beneficiamento e comercialização do óleo, que não estão contabilizados nas análises de margem e markup de comercialização.

Óleo vegetal de copaíba

Em 2006, as 24 famílias pesquisadas extraíram 407 litros do óleo de copaíba, ao custo total de $\mathrm{R} \$ 2.671,55$. Desses custos, $44 \%$ foram gastos com impostos, $40 \%$ com diárias aos extratores, $12 \%$ com materiais para coleta e armazenamento do óleo e cerca de $4 \%$ com frete. O óleo foi vendido ao preço de $\mathrm{R} \$ 30,00$ o litro, gerando uma receita líquida média mensal de $\mathrm{R} \$ 33,83$ por família, representando $9,66 \%$ do salário mínimo vigente em 2006.

A tabela 3 apresenta os preços dos subprodutos elaborados com óleo de copaíba, bem como as margens de comercialização dos diferentes agentes da cadeia produtiva.

Tabela 3. Preços e percentuais da margem de comercialização de produtos elaborados com óleo de copaíba.

Table 3. Prices and percentages of edge of commercialization of products elaborated with oil of copaíba.

\begin{tabular}{lccccc}
\hline Tipo & Variáveis & Produtor & Atacado & Varejo & Margem total \% \\
\hline Óleo in natura & Preço (R\$) & 30,00 & $200,00^{1}$ & $300,00^{2}$ & 90 \\
& Margem (\%) & 7,8 & 56,7 & 33,33 & \\
Sabonete & Preço (R\$) & 30,00 & $200,00^{3}$ & $400,00^{4}$ & 92,5 \\
& Margem (\%) & 5,86 & 42,5 & 50 & \\
\hline
\end{tabular}

${ }^{1}$ Os atacadistas beneficiam e vendem o óleo de copaíba in natura em frascos tipo conta-gotas contendo $30 \mathrm{ml} .{ }^{2}$ Os varejistas vendem os frascos de $30 \mathrm{ml}$ por $\mathrm{R} \$ 9,00$, equivalendo a $\mathrm{R} \$ 300,00$ o litro. ${ }^{3}$ Os atacadistas fabricam e vendem sabonetes, que contêm $25 \mathrm{ml}$ do óleo de copaíba. ${ }^{4}$ Os varejistas vendem os sabonetes a $\mathrm{R} \$ 10,00$ a unidade, o que equivale a R $\$ 400,00$ o litro do óleo de copaíba.

Analisando-se a tabela 3, observou-se que, na comercialização do óleo in natura, $56,7 \%$ da margem de comercialização foi apropriada pelos atacadistas, enquanto o setor varejista apropriou-se de $33,33 \%$, restando apenas $7,8 \%$ para o produtor. A margem total de comercialização foi de $90 \%$.

$\mathrm{Na}$ comercialização dos sabonetes, o varejista se apropriou da maior margem de comercialização (50\%), seguido do atacadista, que se apropriou de $42,5 \%$. O produtor ficou com apenas 5,86\%. A margem de comercialização total foi de $92,5 \%$.

Quanto ao markup de comercialização na cadeia produtiva do óleo de copaíba in natura (Tabela 4), observou-se que o atacadista recebeu uma remuneração de $567 \%$ sobre o preço de compra, enquanto o varejista recebeu 50\%. O preço praticado pelo produtor sofre um acréscimo de $900 \%$ até chegar ao consumidor final. Para a comercialização de sabonetes, o atacadista também é o principal responsável pela alteração de preço, aumentando $567 \%$ o preço pago ao produtor, enquanto que o varejista acrescenta um markup de $100 \%$. O consumidor final paga $1.233 \%$ a mais sobre o preço inicial do produtor.

Tabela 4. Preços e markup de comercialização de produtos elaborados com óleo de copaíba.

Table 4. Prices and commercialization markup of products elaborated with oil of copaiba.

\begin{tabular}{lccccc}
\hline Tipo & Variáveis & Produtor & Atacado & Varejo & Markup total \% \\
\hline Óleo in natura & Preço $(\mathrm{R} \$)$ & 30,00 & 200,00 & 300,00 & 900 \\
& Margem $(\%)$ & 357 & 567 & 50 & \\
Sabonete & Preço (R\$) & 30,00 & 200,00 & 400,00 & 1.233 \\
& Margem (\%) & 357 & 567 & 100 & \\
\hline
\end{tabular}

\section{CONCLUSÕES E RECOMENDAÇÕES}

Os produtos florestais não-madeireiros, além do valor econômico (fonte de renda), constituem fontes de autossubsistência alimentícia, medicinal, além de outros usos, para cerca de 200 mil famílias na 
Amazônia. Entretanto, a produção instável, devido à sazonalidade, representa um conflito com o uso madeireiro.

Observa-se que a carência de informações que os extrativistas têm a respeito do mercado desses produtos é um fator limitante para uma maior geração de renda, além da falta de conhecimento de técnicas de agregação de qualidade e valor aos seus produtos.

Para fortalecer esse processo, devem-se implementar estratégias de marketing, gestão e desenvolvimento de tecnologias que agreguem valor aos produtos da Floresta do Tapajós, pois os benefícios econômicos da exploração desses recursos são pequenos para os extrativistas, se comparados com aqueles recebidos pelos atravessadores, beneficiadores e exportadores.

Os varejistas obtêm a maior fatia da margem com a comercialização do óleo de andiroba in natura $(55,8 \%)$ e dos sabonetes produzidos com óleo de copaíba (50\%). Os atacadistas se apropriam da maior parte da margem na comercialização das velas produzidas com óleo de andiroba (58,6\%) e do óleo de copaíba in natura (56,7\%). Observa-se que os extrativistas são os agentes que menos se apropriam da margem de comercialização dos produtos, devido à baixa agregação de valor dos seus produtos.

Cabe ressaltar que atacadistas e varejistas arcam com custos que não são analisados nas margens e markups de comercialização, por isso não se pode avaliar a margem de lucro desses agentes. Dentro desse contexto, verifica-se que o processo para tomada de decisão sobre a quantificação e determinação do potencial das cadeias produtivas dos PFNMs não é simples e esbarra ainda na falta de informações e dados estatísticos confiáveis sobre esses produtos.

\section{REFERÊNCIAS}

CASTELLANI, D. C. Plantas medicinais e aromáticas: produtos florestais não madeireiros (PFNM). Disponível em: <http://www.ufmt.br/etnoplan/artigos/Plantas\%20medicinais\%20e\%20arom\%E1ticas\% 20-\%20produtos\%20florestais\%20n\%E3o\%20madeireiros.pdf.>. Acesso em: 17/05/2006.

DE BEER, J. H.; MCDERMOTT, M. J. Economic value of non-timber forest products in South-east Asia. Amsterdam: The Netherlands Committee for IUCN, 1989.

EMERY, M. R.; PIERCE, A. R. Interrupting the Telos: Locating Subsistence in Contemporary US Forests. Environment \& Planning A, London: v. 37, n. 6, p. 981-993, 2005.

FAO. Non-wood forest products for rural income and sustainable forestry. Rome, 1995. (Non-wood Forest Products, n. 7).

MOLNAR, A.; Scherr, S. J.; Khare, A. Who Conserves the world's forests? Community-driven strategies to protect forests and respect rights. Washington, DC: Forest Trends and Ecoagriculture Parners, 2004.

NEPSTAD, D. C.; SCHWARZMAN S. (Eds). Non-timber products from tropical forests: evaluation of a conservation and development strategy. New York: New York Botanical Garden, 1992.

PETERS, C. M.; GENTRY, A. H.; MENDELSOHN, R. O. Valuation of an Amazonian Rainforest. Nature, London, v. 339, p. 655-656, 1989.

RUEDA, R. P. Evolução Histórica do extrativismo. Disponível em: <http://www.ibama.gov.br/resex /historia.htm.>. Acesso em: 31/10/ 2006.

SANTOS, A. J.; HILDEBRAND, E.; PACHECO, C. H. P.; PIRES, P. T. L.; ROCHADELLI, R. Produtos não madeireiros: conceituação, classificação, valoração e mercados. Revista Floresta, Curitiba, v. 33, n. 2, p. 215-224, 2003.

SHANLEY, P.; PIERCE, A.; LARIRD, S. Além da Madeira: certificação de produtos florestais nãomadeireiros. Bogor, Indonésia: Centro de Pesquisa Florestal Internacional (CIFOR), 2005a.

SHANLEY, P.; GARCIA, C. O papel dos produtos florestais não madeireiros e o uso múltiplo da floresta. In: OFICINA DE MANEJO COMUNITÁRIO E CERTIFICAÇÃO FLORESTAL NA AMÉRICA LATINA, 2005, Belém. Resultados e propostas. Belém: IMAZON, 2005 b. 